\title{
Tat RNA silencing suppressor activity contributes to perturbation of lymphocyte miRNA by HIV-1
}

\author{
Amy M Hayes ${ }^{1}$, Shuiming Qian ${ }^{1,2}$, Lianbo $\mathrm{Yu}^{3}$ and Kathleen Boris-Lawrie ${ }^{1,2^{*}}$
}

\begin{abstract}
Background: MicroRNA (miRNA)-mediated RNA silencing is integral to virtually every cellular process including cell cycle progression and response to virus infection. The interplay between RNA silencing and HIV-1 is multifaceted, and accumulating evidence posits a strike-counterstrike interface that alters the cellular environment to favor virus replication. For instance, miRNA-mediated RNA silencing of HIV-1 translation is antagonized by HIV-1 Tat RNA silencing suppressor activity. The activity of HIV-1 accessory proteins VprNif delays cell cycle progression, which is a process prominently modulated by miRNA. The expression profile of cellular miRNA is altered by HIV-1 infection in both cultured cells and clinical samples. The open question stands of what, if any, is the contribution of Tat RNA silencing suppressor activity or VprNif activity to the perturbation of cellular miRNA by HIV-1.

Results: Herein, we compared the perturbation of miRNA expression profiles of lymphocytes infected with HIV$1^{\text {NL4-3 }}$ or derivative strains that are deficient in Tat RNA silencing suppressor activity (Tat K51A substitution) or ablated of the vpr/vif open reading frames. Microarrays recapitulated the perturbation of the cellular miRNA profile by HIV-1 infection. The miRNA expression trends overlapped $\sim 50 \%$ with published microarray results on clinical samples from HIV-1 infected patients. Moreover, the number of miRNA perturbed by HIV-1 was largely similar despite ablation of Tat RSS activity and VprNVif; however, the Tat RSS mutation lessened HIV-1 downregulation of twenty-two miRNAs.

Conclusions: Our study identified miRNA expression changes attributable to Tat RSS activity in HIV-1 ${ }^{\text {NL4-3 }}$. The results accomplish a necessary step in the process to understand the interface of HIV-1 with host RNA silencing activity. The overlap in miRNA expression trends observed between HIV-1 infected CEMx174 lymphocytes and primary cells supports the utility of cultured lymphocytes as a tractable model to investigate interplay between HIV-1 and host RNA silencing. The subset of miRNA determined to be perturbed by Tat RSS in HIV-1 infection provides a focal point to define the gene networks that shape the cellular environment for HIV-1 replication.
\end{abstract}

\section{Background}

MicroRNA (miRNA)-mediated RNA silencing is integral to virtually every aspect of biology, including pluripotency, development, differentiation, proliferation, and antiviral defense [1-3]. The activity of miRNA has the capacity to coordinate intricate gene expression networks [2]. Most coding genes exhibit one or many miRNA recognition elements (MRE), and a single miRNA may regulate dozens of genes in response to viral infection or another environmental cue. The

\footnotetext{
* Correspondence: boris-lawrie.1@osu.edu

'Department of Veterinary Biosciences; Center for Retrovirus Research; Center for RNA Biology; Comprehensive Cancer Center, Ohio State University,

Columbus OH, USA

Full list of author information is available at the end of the article
}

mature miRNAs are processed from a primary transcript to a precursor form that is subject to nuclear export. In the cytoplasm, the activity of Dicer, Argonaute (Ago) and TAR RNA-binding protein (TRBP) produces mature miRNA, which is $\sim 22 \mathrm{nt}$ in length [4]. This ribonucleoprotein complex (RNP) is loaded onto a multicomponent RNA-induced silencing complex (RISC), and the miRNA guides the interaction of RISC with one or more partially complementary MRE. MRE interaction with the cognate miRNA guide strand produces sequence-specific RNA silencing by RISC. Virus modulation of miRNA expression or RNA silencing activity has the capacity to counteract antiviral restriction [5].

Collectively, viruses encode proteins and decoy RNAs to counter innate restriction of endogenous and 
exogenous viruses. The interplay between viral infections and miRNA-mediated RNA silencing is best understood in plants. Plant miRNA activity provides a robust antiviral host restriction that is countered by plant virus-encoded RNA silencing suppressors (RSS) that are necessary for viral pathogenesis [6]. RSS have also been found in animal viruses [7], and the list of human viruses that encode an RSS is growing [8]. RSS activity is exhibited by multifunctional RNA binding proteins encoded by ebolavirus $[9,10]$, influenza virus [11], and human T-cell lymphotropic virus type 1 [12]. In the case of ebolavirus, RNA silencing suppressor activity is exhibited by three viral proteins (VP30, VP35, VP40), which suggests an effective counter strike to the small RNA-based host defense is under strong positive selection [10]. Adenovirus expresses abundant levels of VA1 RNA that saturates pre-miRNA nuclear export and pre-miRNA processing to potently reduce miRNA production [13]. In contrast to the generalized downregulation of RNA silencing by VA1, the activity of viral RSS proteins on protein effectors of RNA silencing activity is subtle and conceivably may target a subset of miRNA $[6,8,14,14]$

Several lines of evidence indicate that small RNA activity is important for HIV-1. Cell-encoded miRNA attenuate virus replication in activated $\mathrm{T}$ lymphocytes [15] and in latently infected resting $\mathrm{T}$ lymphocytes [16]. HIV-1 mRNA translation is attenuated by RNA silencing [14], and HIV-1 mRNAs associate and co-localize with components of the RISC [17]. Downregulation of RNA silencing effectors (RCK/p54 or DGCR8) in PBMCs of HIV-1 infected patients on HARRT results in virus reactivation [17]. While RISC activity suppresses HIV-1 replication in at least some circumstances, the small RNA pathway appears to be harnessed to alter cellular gene expression to foster virus replication [18-20].

HIV-1-encoded RNA silencing suppressor activity has been controversial, given differences in experimental conditions [21,22]. Consensus is emerging of an intricate and multifaceted relationship between the human miRNA-mediated silencing pathway and HIV-1 [23] that operates in a strike-counterstrike manner [24]. A cornerstone of this complex relationship is the essential viral transcriptional trans-activator Tat and its cis-acting trans-activation responsive element, TAR. TAR is a structured RNA element within the 5 ' terminus of all HIV-1 transcripts that forms a stem-bulge-stem RNA structure that is recognized by Tat and cellular factors TRBP and P-TEFb to robustly activate productive viral gene transcription. Bennasser and colleagues identified RSS activity in Tat that requires the arginine-rich double-stranded RNA binding domain [21]. Tat RSS activity is genetically separable from Tat transcriptional activity by $\mathrm{K} 51 \mathrm{~A}$ substitution in the double-stranded RNA binding domain [21]. HIV-1 Tat functions across the plant and animal kingdoms to suppress a common step in RNA silencing that is downstream of small RNA maturation [14]. Translation of virion structural protein is exacerbated by K51A substitution in the Tat RNA binding domain (HIV-1 $\left.1^{\mathrm{NL} 4-3} \mathrm{RSS}\right)$ [14]. The delay in HIV-1 replication by Tat K51A substitution can be complemented by TBSV P19 [14] and rice hoja blanca virus non-structural protein 3 (NS3) [25]. Thus, virus interplay with miRNA-mediated RNA silencing is conserved across the plant and animal kingdoms, and Tat RSS activity is important in biology of the human retrovirus, HIV-1.

The potential for RSS activity by TAR RNA was initially identified by Bennasser and colleagues [26]. Similar in principle to adenovirus VA1 RNA, TAR squelches the activity of host protein required for RNA silencing activity. In cells transfected with TAR RNA, TAR acts to occlude TRBP from Dicer and thereby interferes with dsRNA-processing [26]. TAR interaction with TRBP exerts several activities in HIV-1 biology [27-30]. TRBP was originally identified in a cDNA screen for proteins necessary for TAR/Tat transcriptional trans-activation $[31,32]$. Subsequently, TRBP was identified to inhibit the activity of protein kinase $\mathrm{R}$ (PKR) that is directed to double stranded features of viral RNA [33]. The potential for TAR to sequester TRBP and downregulate miRNA maturation or RISC activity [26] is attributable to structural features of the HIV-1 RNA that are processed to viral miRNA [18-20] or to early HIV-1 viral transcripts that are prematurely terminated [34]. In sum, Tat and TAR have the potential to manipulate the RNA silencing pathway in a strike-counter-strike manner $[23,24]$. The resulting alteration of the cellular environment may tip the balance to favor virus replication or favor viral latency. The identification of the miRNA affected by HIV-1 RSS activity and future determination of the MRE targeted by these miRNA, are strategic milestones in the process to understand the viral interface with host RNA silencing.

MiRNAs contribute to physiological control of the cell cycle [35]. Hsa-miR-17-5p modulates the G1/S transition by targeting over twenty genes that regulate progression of the cell cycle [36]. The broadly conserved miRNA let-7 family controls exit from the cell cycle in Caenorhabditis elegans [37]. Human fibroblasts arrest in G2/M by overexpression of let-7 family members [38]. In human cancers, tumor progression is attributable to dysregulation of cell cycle control by miRNA $[39,40]$. G2/M delay is a feature of HIV-1 infected cells that is attributable to the HIV-1 accessory proteins Vpr and Vif [41-43]. Ablation of $v p r / v i f$ restores cell cycle profiles to be similar to uninfected cells [43]. A primary role for $\mathrm{Vpr}$ is to trans-activate viral gene expression during 
virus-induced $\mathrm{G}_{2} / \mathrm{M}$ delay $[41,44,45]$. A primary role of Vif is to combat antiviral restriction by APOBEC proteins $[46,47]$. Vif additionally contributes to downregulation of $\mathrm{Vpr}$, which would reduce transcription transactivation [48]. The possibility remains to be addressed that $\mathrm{Vpr}$ and Vif contribute to perturbation of cellular miRNA by HIV-1, perhaps by trans-activation. A necessary step in the process to understand interplay of the virus with host RNA silencing is the definition of miRNA expression differences during infection with HIV-1 or Vpr/Vif-deficient HIV-1.

Herein, we have evaluated the perturbation of miRNA signature of cultured lymphocytes by HIV-1 and HIV-1 derivatives deficient in $\mathrm{Vpr} / \mathrm{Vif}(\Delta \mathrm{VV})$ or Tat RSS (RSS). Our results indicate that the miRNA signature is perturbed by HIV-1 infection, and a subset of miRNA is differentially expressed by elimination of the HIV-1 Tat RNA silencing antagonist. Additionally, we observed $\sim 50 \%$ overlap between the miRNA signatures of cultured lymphocytes infected with HIV-1 and clinical samples from HIV-1 infected individuals. The outcomes are a list of candidate miRNAs that interface with cellular genes important to HIV-1 replication, and a tractable model to investigate the interplay between HIV-1 and cellular miRNA that alters the cellular environment during virus infection.

\section{Results}

Comparison of miRNA expression profiles produced by HIV-1 and strains deficient in Tat RSS or Vpr/Vif Three strains of HIV-1 ${ }^{\mathrm{NL} 4-3}$ were propagated by transfection of provirus (Figure 1) into HEK293 cells, and cell-free virus was used to generate HIV-1/CEMx174 lymphocytes. HIV-1 infection by cell-free HIV-1 is relatively inefficient unless enhanced by spinoculation $[49,50]$, whereas HIV-1 infection by co-culture is efficient [51]. All experiments were carried out by co-culture infection of CEMx174 lymphocytes to minimize the confounding signal from uninfected cells. We monitored the progression of the infection by FACS of intracellular Gag at several intervals. The benchmark criterion for lymphocyte harvest was set at $\geq 80 \%$ infection in order to minimize the background signal from residual uninfected cells. Comparison of HIV-1 ${ }^{\mathrm{NL} 4-3}$ to the derivative strains $\triangle \mathrm{VV}$ and RRS revealed differences in replication kinetics, similar to previous observations [21,52]. The FACS of intracellular Gag at $\sim 12 \mathrm{~h}$ intervals determined that $\mathrm{HIV}-1^{\mathrm{NL} 4-3}$ and $\triangle \mathrm{VV}$ reached $\geq 80 \%$ infection by 40 to $48 \mathrm{hr}$, while RSS reached $\geq 80 \%$ infection by $60 \mathrm{hr}$ (Table 1). Cell viability was monitored by trypan blue exclusion and was determined to be $\geq 90 \%$ at time of harvest. Total cellular RNA was harvested from replicate infections and subjected to bioanalyzer analysis to verify integrity. The RNA samples were treated with reverse

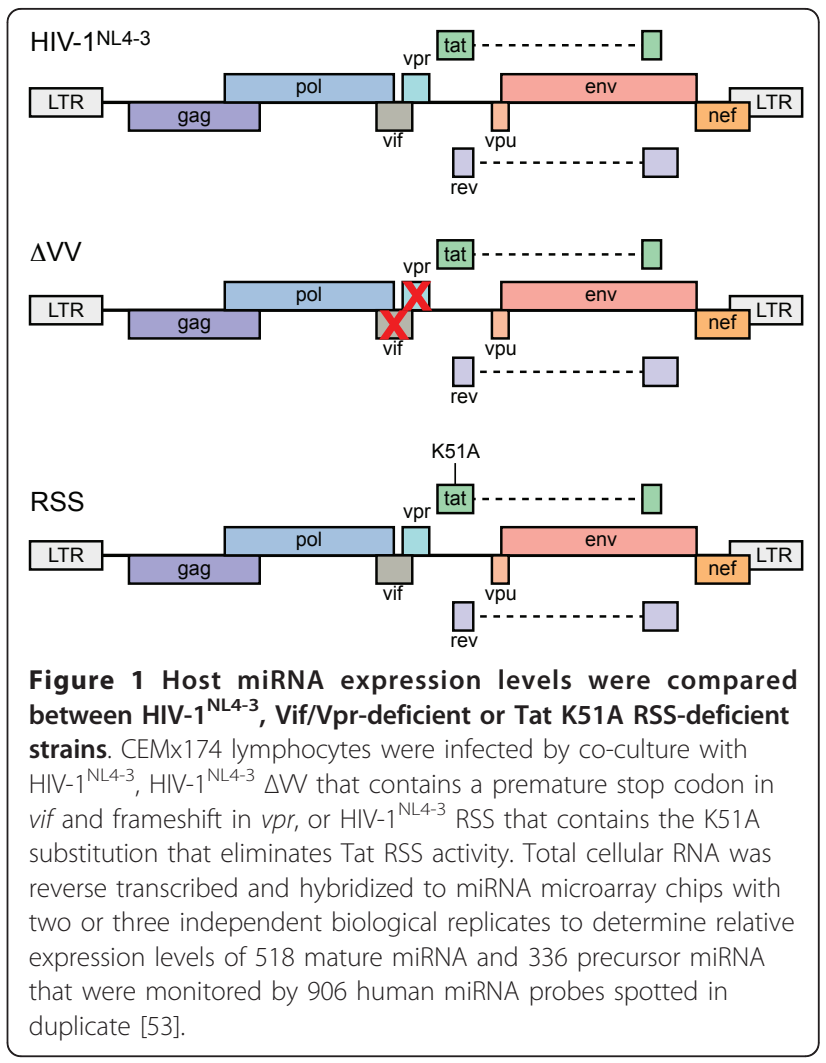

transcriptase and random hexamer primer, and biotinylated cDNA was generated for hybridization by the miRNA microarray shared resource of the Ohio State University Comprehensive Cancer Center. Two replicate experiments used miRNA microarray chips printed with 906 duplicate probes that measure levels of 518 mature miRNA and 332 precursor miRNA [53]; four probes were excluded because they have been deleted from miRBase. Signal intensity from two independent infections per virus was quantified with GenePix Pro 6 image analysis software, and the data were evaluated for background correction, log base 2 transformation, and quantile normalization. Microsoft Excel pivot tables were used to manage comparative expression trends for viral strains. Signal intensities in $\log _{2}$ values ranged from 0.3 to 16.0 ; and a signal intensity of $\log _{2}$ value of 5 or

Table 1 Percentage of CEMx174 infected cells at time of RNA harvest

\begin{tabular}{ccccc}
\hline & \multicolumn{4}{c}{ Percentage of Virus Infected Cells a } \\
\cline { 2 - 5 } Experiment & Mock & HIV-1 & RSS & \multicolumn{1}{c}{$\mathbf{V V}$} \\
\hline Replicate 1 & 0 & 90 & 83 & 80 \\
Replicate 2 & 0 & 95 & 87 & 90 \\
\hline
\end{tabular}

${ }^{\text {a }}$ CEMx174 cells were infected by co-culture and the progression of infection was monitored by FACS of intracellular Gag. Values indicate the percentage of $\mathrm{Gag}^{+}$cells at time of harvest. Total cellular RNA was prepared in Trizol, integrity verified by bioanalyzer and processed for the miRNA microarrays. 
below was considered below minimally detectable limits. Signal intensities in $\log _{2}$ values greater that 16 corresponded to saturation of signal. MiRNA expression was considered changed if upregulated 2-fold or downregulated by a factor of 2 or more. Four categories of miRNA expression were enumerated: Up; Down; No change (levels remained within a factor of 2 of uninfected control); or Less than the minimum detectable.

The miRNA signature is perturbed by HIV-1 and derivatives deficient in vpr/vif or Tat RSS

HIV-1 perturbed the expression of $\sim 200$ of the 518 mature miRNAs on the chip; 70 miRNAs were upregulated and 100 miRNAs were downregulated (Table 2). The number of up- or down-regulated miRNAs was similar between HIV-1 ${ }^{\text {NL4-3 }}, \Delta \mathrm{VV}$ and RSS (Table 2). Scatterplot analysis of the expression changes relative to mock infection revealed the range of expression differences was similar among the infections (Figure 2). Fiftytwo miRNAs were upregulated by all three strains, and eighty-three miRNAs were downregulated by all three strains.

We examined the data for miRNAs that exhibited $\geq 2$ fold expression change between the viral strains. As shown in scatterplot analysis between HIV-1 and $\Delta \mathrm{VV}$, five miRNAs fall outside the two-fold change lines (Figure 3); HIV-1 exhibited $\geq 2$-fold greater expression of hsa-miR-32, hsa-miR-194, hsa-miR-199a, hsa-miR-496, and expression of hsa-miR-450 was reduced. The results indicate that ablation of vif/vpr modestly alters miRNA profile. We expected this minor difference is attributable to experimental variation, and this issue would be resolved by additional experiments. By comparison, the scatterplot analysis unveiled nineteen miRNAs that exhibited expression differences between HIV-1 and RSS (Figure 3, Table 3). The results indicate that perturbation of the cellular miRNA signature by HIV-1 infection is largely independent of the activity of $v p r / v i f$ or Tat RSS.

Table 2 Distribution of changes in mature miRNA expression relative to uninfected lymphocytes for infection with indicated viral strain

\begin{tabular}{cccc}
\hline & \multicolumn{3}{c}{ Infection Relative to Mock $^{\mathbf{a}}$} \\
\cline { 2 - 4 } Expression Trend $^{\text {b }}$ & HIV-1 & RSS & \multicolumn{1}{c}{$\boldsymbol{\Delta V}$} \\
\hline Up & 72 & 74 & 74 \\
Down & 106 & 104 & 111 \\
No change & 157 & 153 & 146 \\
<MD & 234 & 238 & 238 \\
\hline
\end{tabular}

\footnotetext{
${ }^{a}$ Human CEMx174 lymphocytes infected by co-culture with indicated virus were screened by miRNA microarray. The number of mature miRNA probes present on the chip was 518 after exclusion of four probes removed from miRBase. Values represent number of probes affected. ${ }^{b}$ Up: upregulated $(\geq 2.0$ $x)$; Down: downregulated $(\leq 0.5 \times)$; No change: between $0.5-2.0 \times ;<M D$ : less than minimum detectable limits.
}

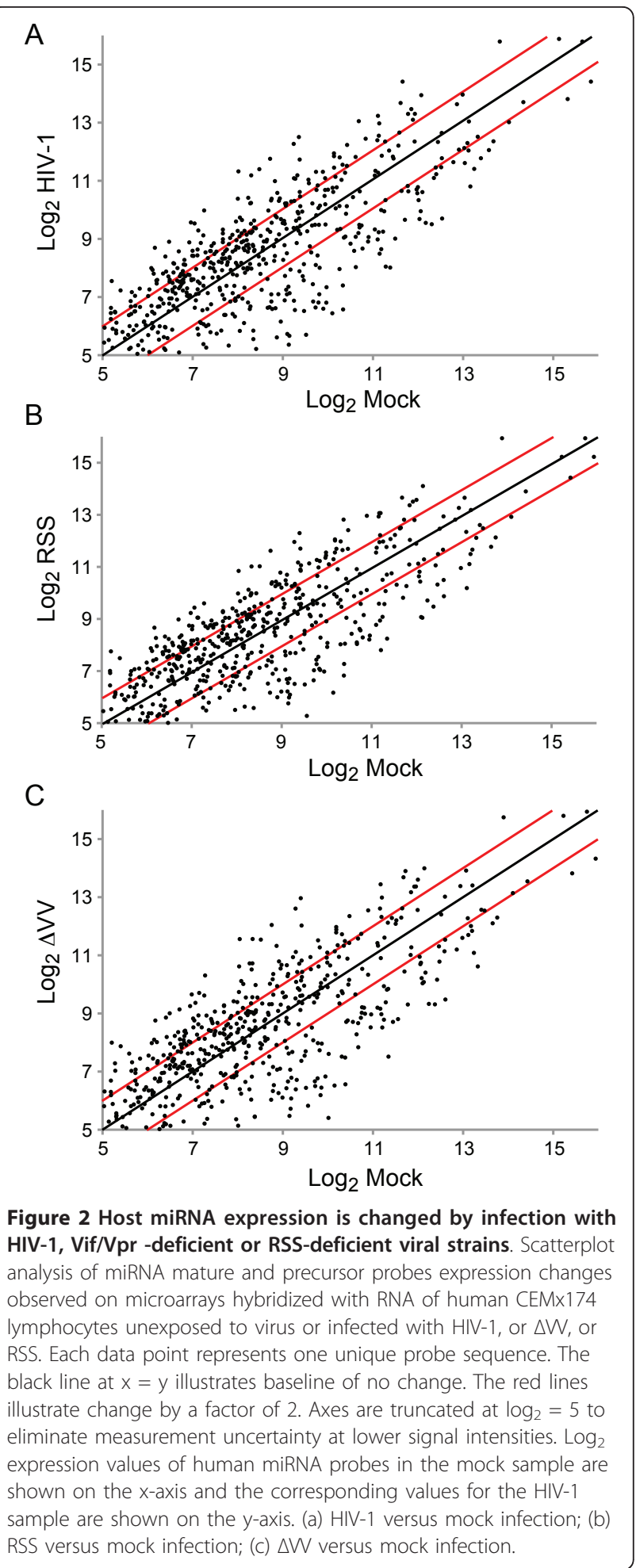

Tat RSS mutation affects the steady state of a subset of miRNA

HIV-1 exhibited 2 to 3 -fold greater expression of fifteen miRNA relative to RSS (Table 3). Four miRNA were downregulated in HIV-1 relative to RSS by a factor of 2 


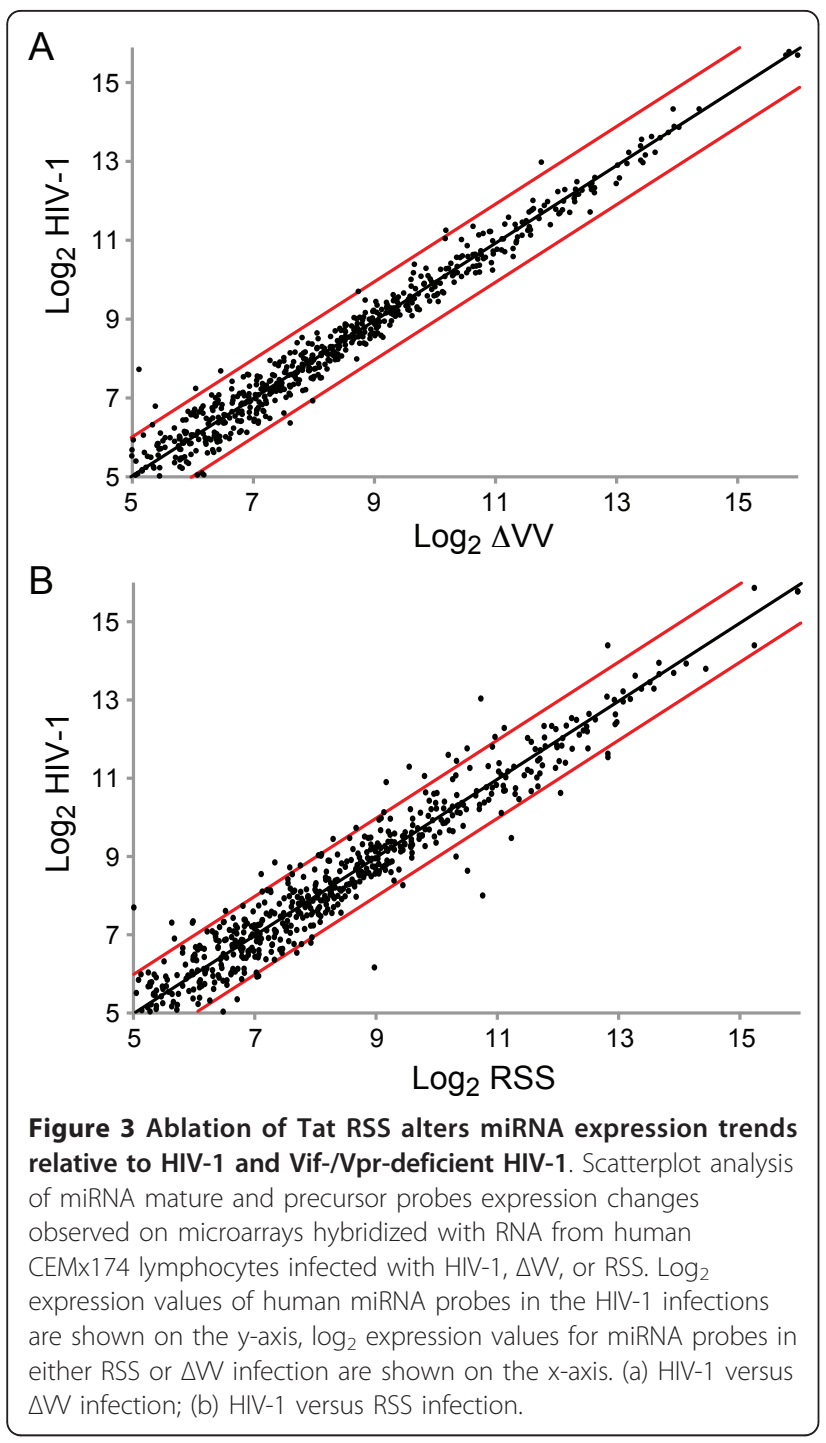

to 4 (Table 3). Of the 145 miRNA perturbed by the three viral infections relative to cells without virus infection (mock), Tat RSS activity in HIV-1 correlated with higher steady state for 15 of the 18 and lower steady state for 3 miRNA (Table 4). These differences may be attributable to direct effects of Tat RSS activity on RNA stability or by secondary effects elicited through upstream genes. In sum, the observed generalized perturbation of miRNA expression by HIV-1 infection of cultured lymphocytes is consistent with previous microarrays of HIV-1 infected cells $[15,54,55]$. The comparison of the three derivative viruses determined that the generalized perturbation of miRNA expression levels by HIV-1 is largely independent of the ablation of $\mathrm{Vpr} / \mathrm{Vif}$ and Tat RSS.

The miRNA that were downregulated by all three viral infections $(n=83)$ were filtered to ascertain possible differences in the level of downregulation. Twenty-two
Table 3 Mature miRNAs that exhibit expression change by a factor of $\geq 2$ for RSS relative to HIV-1 infection

\begin{tabular}{cc}
\hline $\begin{array}{c}\text { MiRNAs differing in expression by } \mathbf{2} \mathbf{2} \text { between RSS and HIV-1 } \\
\text { MiRNA Probe }\end{array}$ & 2.1 \\
\hline Upregulated & 2.1 \\
hsa-miR-105 & 2.2 \\
hsa-miR-550 1
\end{tabular}

miRNA exhibited less downregulation by $10 \%$ or more in RSS compared to HIV-1 or $\Delta \mathrm{VV}$ infection ( $\mathrm{p}=$ $\leq 0.0001$ ) (Table 5). Subsequent investigations are warranted to evaluate the possibility that these miRNA have conserved features and to determine the MRE that are

Table 4 Mature miRNAs that exhibit expression change by a factor of $\geq 2$ between RSS and HIV-1 infection standardized to mock

\begin{tabular}{|c|c|c|c|c|}
\hline & & \multicolumn{3}{|c|}{ RSS Relative to Mock ${ }^{a}$} \\
\hline & & Up & Unchanged & Down \\
\hline & Up & hsa-miR-494 & $\begin{array}{l}\text { hsa-miR-194 } \\
\text { hsa-miR-500 }\end{array}$ & - \\
\hline Relative & Unchanged & - & $\begin{array}{l}\frac{\text { hsa-miR-33b }}{\text { hsa-miR-105b }} \\
\text { hsa-miR-453 } \\
\text { hsa-miR-499 }\end{array}$ & $\begin{array}{c}\text { hsa-miR-17-5p } \\
\text { hsa-miR-20a } \\
\text { hsa-miR-20b } \\
\text { hsa-miR-30e-3p } \\
\text { hsa-miR-106a } \\
\text { hsa-miR-219 }\end{array}$ \\
\hline Mock & Down & - & - & $\begin{array}{l}\text { hsa-miR-21 } \\
\text { hsa-miR-26b } \\
\frac{\text { hsa-miR-32 }}{\text { hsa-miR-215 }} \\
\text { hsa-miR-658 }\end{array}$ \\
\hline
\end{tabular}

${ }^{a}$ Nineteen miRNAs exhibited expression differences between the indicated strains relative to mock infection. The miRNAs indicated in plain font exhibited reduced expression by a factor of 2 or more for RSS compared to HIV-1. The three miRNAs in underlined font exhibited increased expression by 2-fold or more for RSS compared to HIV-1. Notably, miR550 upregulation by HIV-1 was attenuated in RSS infection (Table 3 ) but is excluded from Table 4 because miR550 was not detectable in cells lacking virus (mock infection). 
Table 5 Downregulation of selected miRNAs is diminished by RSS mutation

\begin{tabular}{|c|c|c|c|c|c|}
\hline \multirow[b]{2}{*}{ miRNA } & \multicolumn{3}{|c|}{ Downregulation Relative to Mock Infection ${ }^{a}$} & \multicolumn{2}{|c|}{ Lessened Downregulation for RSS Relative to Indicated Infection } \\
\hline & HIV-1 & RSS & $\Delta \mathrm{VV}$ & HIV-1 & $\Delta \mathrm{VV}$ \\
\hline hsa-miR-10a & $26 \%$ & $43 \%$ & $32 \%$ & $17 \%$ & $10 \%$ \\
\hline hsa-miR-23a & $19 \%$ & $34 \%$ & $22 \%$ & $15 \%$ & $11 \%$ \\
\hline hsa-miR-25 & $27 \%$ & $43 \%$ & $15 \%$ & $17 \%$ & $28 \%$ \\
\hline hsa-miR-27a & $31 \%$ & $37 \%$ & $18 \%$ & $6 \%$ & $19 \%$ \\
\hline hsa-miR-30d & $34 \%$ & $54 \%$ & $30 \%$ & $20 \%$ & $25 \%$ \\
\hline hsa-miR-32 & $11 \%$ & $24 \%$ & $4 \%$ & $13 \%$ & $19 \%$ \\
\hline hsa-miR-92 & $33 \%$ & $50 \%$ & $33 \%$ & $17 \%$ & $17 \%$ \\
\hline hsa-miR-95 & $39 \%$ & $51 \%$ & $41 \%$ & $12 \%$ & $10 \%$ \\
\hline hsa-miR-99b & $46 \%$ & $53 \%$ & $33 \%$ & $7 \%$ & $20 \%$ \\
\hline hsa-miR-100 & $24 \%$ & $35 \%$ & $19 \%$ & $11 \%$ & $16 \%$ \\
\hline hsa-miR-103 & $46 \%$ & $53 \%$ & $37 \%$ & $6 \%$ & $16 \%$ \\
\hline hsa-miR-107 & $42 \%$ & $51 \%$ & $31 \%$ & $8 \%$ & $20 \%$ \\
\hline hsa-miR-125b & $16 \%$ & $26 \%$ & $19 \%$ & $10 \%$ & $7 \%$ \\
\hline hsa-miR-128 & $26 \%$ & $47 \%$ & $29 \%$ & $21 \%$ & $19 \%$ \\
\hline hsa-miR-135a & $23 \%$ & $35 \%$ & $18 \%$ & $12 \%$ & $17 \%$ \\
\hline hsa-miR-142-5p & $24 \%$ & $30 \%$ & $20 \%$ & $5 \%$ & $10 \%$ \\
\hline hsa-miR-148b & $37 \%$ & $49 \%$ & $39 \%$ & $12 \%$ & $10 \%$ \\
\hline hsa-miR-181a & $40 \%$ & $53 \%$ & $47 \%$ & $13 \%$ & $6 \%$ \\
\hline hsa-miR-186 & $50 \%$ & $64 \%$ & $50 \%$ & $14 \%$ & $14 \%$ \\
\hline hsa-miR-193a & $40 \%$ & $69 \%$ & $44 \%$ & $29 \%$ & $24 \%$ \\
\hline hsa-miR-369-3p & $27 \%$ & $41 \%$ & $39 \%$ & $14 \%$ & $2 \%$ \\
\hline hsa-miR-376a & $43 \%$ & $59 \%$ & $43 \%$ & $16 \%$ & $15 \%$ \\
\hline hsa-miR-379 & $40 \%$ & $61 \%$ & $47 \%$ & $21 \%$ & $14 \%$ \\
\hline hsa-miR-423 & $44 \%$ & $65 \%$ & $24 \%$ & $21 \%$ & $41 \%$ \\
\hline hsa-miR-601 & $31 \%$ & $38 \%$ & $21 \%$ & $7 \%$ & $17 \%$ \\
\hline hsa-miR-660 & $40 \%$ & $66 \%$ & $42 \%$ & $26 \%$ & $24 \%$ \\
\hline hsa-miR-671 & $36 \%$ & $47 \%$ & $46 \%$ & $11 \%$ & 0 \\
\hline
\end{tabular}

${ }^{a}$ Expression trend compared to uninfected CEMx174 lymphocytes (Mock). Bold designates miRNAs downregulated in PBMC of HIV-1 patients [55].

${ }^{b}$ Percentage increase between RSS relative to indicated strain.

targeted by these miRNA. These trends are consistent with removal of RSS activity that affects the steady state of this subset of miRNA.

\section{Comparison of miRNA expression trends in clinical samples and cultured lymphocytes}

The microarrays are useful to gauge expression trends but RT-quantitative PCR (qPCR), and other more sensitive and specific assays are required to quantify expression differences $[53,56]$. For independent assessment of the miRNA expression trends, we performed RT-qPCR with Taqman miRNA assays. We evaluated hsa-miR-29a, hsa-miR-198, hsa-miR-128, hsa-miR-214 because they are reported to target HIV-1 or to possess antiviral activity $[57,58]$. The snoRNA RNU48 provided an internal control that has been useful in qPCR analysis of miRNA [59,60]. A series of dilution curves determined the efficiency of each Taqman probe (data not shown), and the expression changes were determined in RNA samples from HIV-1, $\Delta \mathrm{VV}$ and RSS infections and uninfected lymphocytes (Mock) from independent replicate infections. Triplicate assays were performed, and miRNA levels were quantified with efficiency correction; and the data are presented relative to the internal control RNU48. Results are expressed as fold change relative to the mock control by the $\Delta \Delta \mathrm{C}_{\mathrm{T}}$ method [61].

The upregulation of hsa-miR-214 and hsa-miR-198 by the three virus strains was confirmed by RT-qPCR (Table 6). The qPCR measured greater upregulation (8-fold) than the microarray (2-fold), consistent with greater sensitivity for the Taqman probes relative to the hybridization probes. Hsa-miR-214 is reported to exhibit broadly active antiviral activity [57], and hsamiR-198 has been shown to target cyclin T1, a host cellular protein necessary for Tat transcriptional transactivation [62]. Over expression of hsa-miR-198 has been shown to reduce HIV-1 gene expression and replication [62]. Therefore, the observed upregulation would be expected to deter viral replication. The 
Table 6 Comparison of expression trends identified by microarray or RT-qPCR in independent RNA preparations

\begin{tabular}{|c|c|c|c|}
\hline \multirow[t]{2}{*}{ Expression Trend in Microarrays } & \multicolumn{3}{|c|}{ Expression Relative to Mock Measured by $\mathrm{qPCR}^{\mathrm{a}}$} \\
\hline & HIV-1 & RSS & $\Delta \mathrm{VV}$ \\
\hline \multicolumn{4}{|l|}{ Upregulated } \\
\hline hsa-miR-198 & $8.3 \pm 1.0$ & $8.3 \pm 2.2$ & $9.5 \pm 0.3$ \\
\hline hsa-miR-214 & $8.6 \pm 4.5$ & $15.3 \pm 5.4$ & $12.7 \pm 5.7$ \\
\hline \multicolumn{4}{|l|}{ Downregulated } \\
\hline hsa-miR-29a & $0.8 \pm 0.1$ & $0.6 \pm 0.1$ & $1.0 \pm 0.3$ \\
\hline hsa-miR-128 & $1.1 \pm 0.4$ & $1.0 \pm 0.2$ & $0.9 \pm 0.1$ \\
\hline
\end{tabular}

${ }^{a}$ Change in expression for indicated miRNAs was measured by qRT-PCR using Taqman probes in independent RNA preparations of HIV-1, RSS, $\triangle$ VV, and mock infected cells. Values for quantitative RT-PCR are derived from at least three replicate experiments, and expressed relative to mock. Relative expression differences were calculated using the $\Delta \Delta C_{\mathrm{T}}$ method with efficiency correction and RNU48 as the internal control.

outcome of the upregulation of these miRNAs in the context of HIV-1 infected CD $4^{+} \mathrm{T}$ cells will be an important followup study.

The downregulation of hsa-miR-128 was not recapitulated by the RT-qPCR assay and the levels of hsa-miR29a were downregulated, but less than the 2 -fold cutoff (Table 6). The signal intensities measured for these miRNA by qPCR and the microarray were within normal ranges for detection. We expect the discrepancy is attributable to differences in microarray probe efficiency relative to $\mathrm{qPCR}$. We repeated the $\mathrm{qPCR}$ with primers that amplify the precursor miR-29a and observed downregulation by a factor of 2 for the pre-miRNAs (data not shown), which is consistent with reduced expression. Microarrays by Houzet et al. [55] identified hsa-miR-29a downregulation in HIV-1 infected lymphocytes, consistent with the trends in our microarrays. These results emphasize the utility of microarrays to screen for differences in expression and that more sensitive and specific approaches are required to quantify expression differences. Because microarray studies have been used to assign HIV-1 miRNA expression signatures in a variety of cultured cells and clinical specimens, we investigated their overlap with the HIV-1 miRNA expression signatures in our study.

We evaluated our datasets against a published miRNA microarray analysis of patient samples to identify miRNA expression changes, if any, that are sustained among the HIV-1 infection models. Houzet et al. studied a cohort of twelve uninfected controls and thirtysix HIV-1 infected patients, who were stratified into four groups by CD4+ T cell count and viral load [55]. Microarray analysis of PBMC identified sixty-two miRNA that were modulated relative to the uninfected cohort. The criteria for differential expression was a change by a factor of 2 or more in $>50 \%$ of patients in at least one of four different groups. Additionally, samples of naive PBMC were infected with HIV $-1^{\text {NL4-3 }}$ or treated with anti-CD3 to activate $\mathrm{T}$ cells and subjected to miRNA microarray. The results identified an additional thirty-one miRNA probes with expression modulation by a factor of 2 or more in at least one of these samples. These miRNAs were represented by probes in our microarray analyses, although twenty-four exhibited signal intensities below minimum detectable limits (Figure 4, designated in italics).

Of the sixty-two miRNAs with modulated expression in HIV-1 infected patients, thirty-three exhibited similar change in expression in CEMx174/HIV-1 ${ }^{\text {NL4-3 }}$ (Figure 4) and CEMx174/RSS and CEMx174/DVV (data not shown). Of these, thirty-two miRNAs exhibited downregulation (designated in blue). One miRNA was upregulated in both the patient dataset and in CEMx174/HIV-1 ${ }^{\text {NL4-3 }}$ (designated in red). Thirteen miRNAs that exhibited expression modulation in the patient dataset were unchanged in CEMx174/HIV$1^{\text {NL4-3 }}$ (Figure 4 , miRNAs in plain font that are excluded from CEMx174/HIV-1 ${ }^{\mathrm{NL} 4-3}$ ). Fourteen miRNAs present in patients were below detectable limits in CEMx174/HIV-1 ${ }^{\mathrm{NL} 4-3}$ (Figure 4, italics). A reversed expression trend was observed for hsa-miR-150 and hsa-miR-337 (Figure 4, underline), which were downregulated in patient PBMC and upregulated in CEMx $174 / \mathrm{HIV}-1^{\mathrm{NL} 4-3}$. Six instances of reversed expression trend (Figure 4, underline) were observed between naive PBMC/HIV-1 ${ }^{\mathrm{NL} 4-3}$ and CEMx174/HIV$1^{\mathrm{NL} 4-3}$. Overall, there was approximately $50 \%$ overlap between CEMx174/HIV-1 ${ }^{\mathrm{NL} 4-3}$ and patient samples. Houzet et al. had observed similar overlap in their comparison of naive PBMC/HIV-1 ${ }^{\mathrm{NL} 4-3}$ and uninfected activated $\mathrm{T}$ cells [55]. We consider the $50 \%$ overlap between CEMx174/HIV-1 ${ }^{\text {NL4-3 }}$ and patient samples to be appreciable given the differences in cell lineage, infection parameters and the admixture of uninfected cells in blood samples from patients [63]. We speculate that the overlap identified with patient PBMCs, despite the admixture with uninfected cells, is attributable to paracrine signaling or another bystander effect that is not solely seen by $\mathrm{T}$ cell activation. The results support the utility of the cultured lymphocytes as a valid model to refine experimental design and interpretation of data from patient samples. 


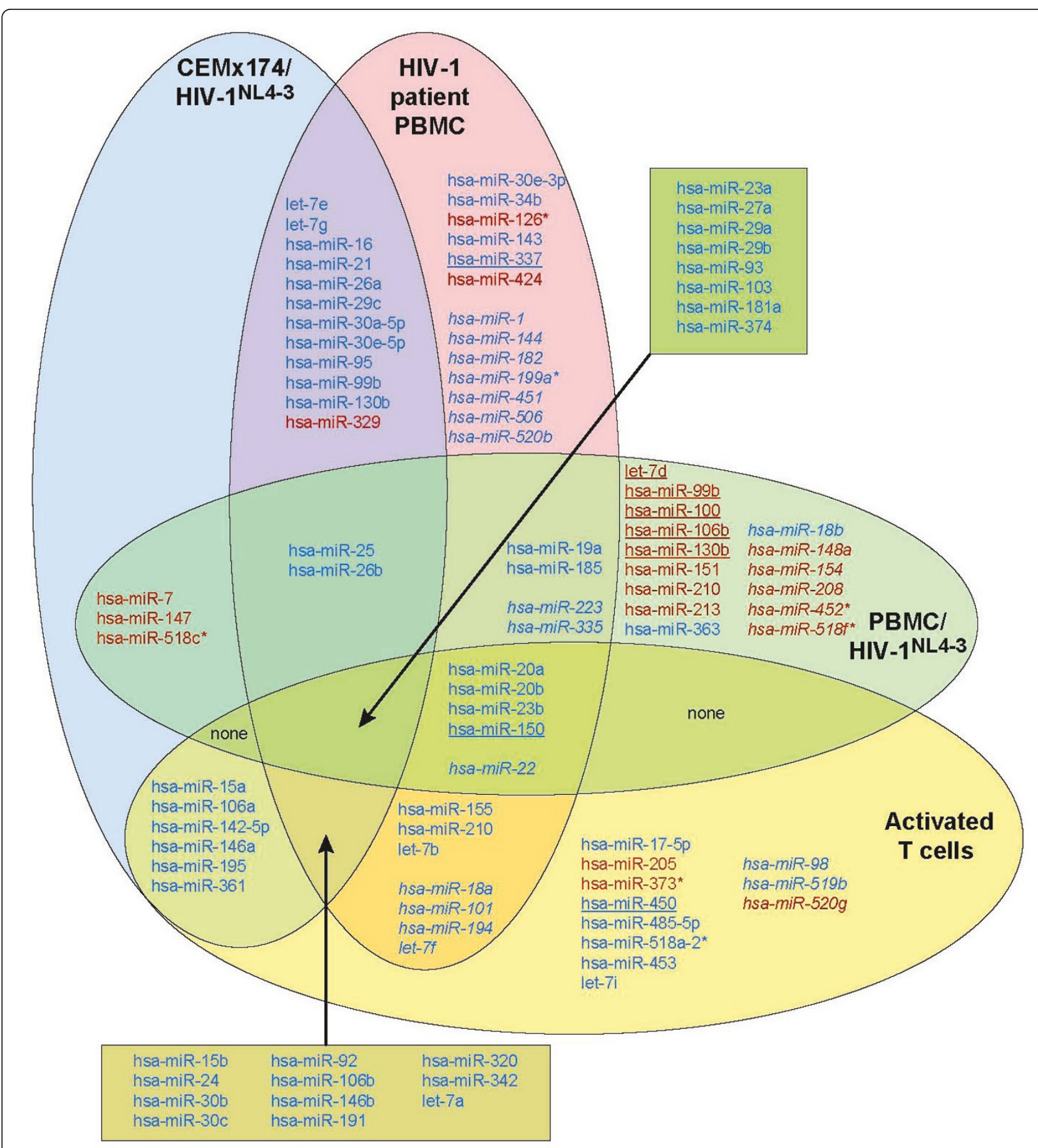

Figure 4 Venn diagram determined overlap between clinical and cultured HIV-1 infected cells. Venn diagram integrating miRNA expression trends from four datasets that are designated by labeled oval: CEM $174 / \mathrm{HIV}-1^{\mathrm{NL} 4-3}$ (this study); primary PBMC/HIV- ( $^{\mathrm{NL} 4-3}$; uninfected T cells activated with anti-CD3; and PBMC of HIV-1 infected patients [55]. MiRNA upregulated by $\geq 2$ are designated in red; miRNA downregulated by a factor of $\geq 2$ are designated in blue; miRNA designated by underscore exhibit discordant expression in CEMx $174 /$ HIV- ${ }^{\text {NL4-3 }}$. Asterisk: miRNA nomenclature designating the less abundant product of a precursor hairpin [69]. 


\section{Discussion}

Removal of Tat RSS activity affects expression of a subset of miRNA

This study determined that perturbation of miRNA expression by HIV-1 is largely independent of vif/vpr and Tat RSS activity in culture lymphocytes. One-hundred and forty-five miRNA were perturbed by infection with HIV-1 ${ }^{\mathrm{NL} 4-3}$, the Tat RSS-deficient derivative, and the vif/vpr-deficient derivative. Eighty-three miRNA were downregulated and ablation of the HIV-1 Tat RNA silencing suppressor (K51A) lessened the downregulation of twenty-two miRNA ( $\mathrm{p}=\leq 0.0001)$ (Table 5). The RSS activity of Tat requires the RNA binding domain and in transfected cells functions at a late step in the RNA silencing pathway after miRNA maturation [14]. We also previously determined that HIV-1 Tat RSS activity is functionally interchangeable with TBSV P19 in animal cells and in plant cells [14]. The crystal structure and biochemical analysis of TBSV P19 have determined the P19 RNA binding domain recognizes selected small RNAs by their particular structural features [64]. By analogy, Tat recognizes TAR RNA by structural features that resemble miRNA duplex regions. Conceivably, a pseudo-TAR-Tat interaction poses as a decoy substrate for TRBP that suppresses localized RNA silencing activity [26]. Herein, the complex is inaccessible for RISC loading or in an aberrant RISC. The aberrant RISC might irreversibly capture the miRNA in cognate MREs. Structural predictions posited in MirBase of several miRNAs differentially regulated by RSS exhibit a Ubulge feature that resembles TAR. We speculate that Tat RSS activity on selected cellular miRNA is a fortuitous outcome of a structural resemblance to TAR, which spares RNA silencing of their cognate MREs. Future analysis of such a TAR-mimic hypothesis and determination of the MRE of the miRNA modulated by Tat RSS are necessary steps in the process to understand the complex interface of HIV-1 with host RNA silencing activity.

The explanations for perturbation of miRNA expression levels include a primary effect of HIV-1 on the stability of the miRNA or secondary effect on the expression of the miRNA locus. A recent study of the fate of miRNA subsequent to MRE regulation using an inducible expression system determined that productive interaction of miR223 with cognate MRE accelerates the rate of decay of the miRNA [65]. A corollary scenario is that HIV-1 Tat RSS sequesters the miRNA from productive interaction with cognate MRE and indirectly slows the miRNA's rate of decay. Consistent with this possibility, 15 of the 19 miRNAs differentially expressed in HIV-1 versus RSS exhibited greater abundance in the HIV-1 infection (Table 3). Comparison of miRNA trends relative to mock infection revealed 6 of the 11 miRNAs downregulated in RSS possessed unchanged expression in HIV-1 infection, and 2 of the 6 miRNAs with expression unchanged in RSS infection were upregulated in HIV-1 infection (Table 4). Future studies are warranted to determine the biophysical mechanism for Tat RSS interaction with selected miRNA, to measure the stability of the miRNA subject to Tat RSS activity, and the efficiency of the cognate MRE recognition and regulation.

\section{Little change in miRNA profile is observed by ablation of Vpr/Vif}

The possibility that HIV-1 manipulation of host miRNA contributes to HIV-1 induced cell cycle delay was posited by the prominent role of miRNA in cell cycle progression. Of particular interest are the let-7 family members, whose role in cell cycle progression is broadly conserved from Caenorhabditis elegans to human $[37,38]$. Overexpression of let-7 family members leads to G2/M arrest in human fibroblasts [38]. Furthermore, hsa-miR-21 modulates cell cycle through regulation of BTG family member 2, a transcriptional coregulator of the cyclin D1 promoter that is dysregulated in laryngeal cancer [39]. Hsa-miR-15a and hsamiR-16 regulate the cell cycle and are downregulated or deleted in some non-small cell lung tumors [40]. Expression differences were not observed for hsa-miR16 or has-miRNA-15a in our analysis of HIV-1 and Vpr/Vif-deficient HIV-1. Hsa-miR-17-5p, which is suppressed by $\mathrm{HIV}-1$, modulates the G1/S transition by targeting over 20 genes that regulate progression of the cell cycle [36]. An additional role for hsa-miR-17$5 \mathrm{p}$ is regulation of the Tat transcriptional cofactor PCAF $[15,66]$. Therefore downregulation of hsa-miR17-5p expression by HIV-1 would be expected to produce pleiotropic effects that emanate from increased viral gene transcription. Hsa-miR-17-5p is downregulated by a factor of 2 in HIV-1 infected CEMx174 cells and downregulation in $\triangle \mathrm{VV}$ is similar, suggesting Vif/ Vpr expression does not alter expression of this miRNA. Our assessment determined that expression of several let- 7 family members is perturbed by HIV-1 with overlap displayed between CEMx174/HIV-1 infections and cultured lymphocytes, patient PBMC and activated $\mathrm{T}$ cells (Figure 4 ). In each case, the expression trends were similar between HIV-1 and $\Delta \mathrm{VV}$. In conclusion, our results did not unveil an effect of ablation of $v p r / v i f$ on these miRNA that affect cell cycle progression. The possibility remains that other HIV-1 gene products or miRNA feedback loops for cell cycle progression contribute to HIV-1 induced G2/M delay in lymphocytes. 
Trends overlap between infection models for several miRNAs known to affect HIV-1 replication

We observed the perturbation of eight miRNAs known to play a role in HIV-1 infection (Table 7). These miRNAs target HIV-1 mRNA or host genes required for virus replication. Two members of the hsa-miR-17/92 cluster, hsa-miR-17-5p and hsa-miR-20a, target the mRNA of the PCAF cofactor of Tat trans-activation. Our results and published microarrays agree in downregulation of these miRNA by HIV-1 [54,55]. Their perturbation in HIV-1 infection is near the 2 -fold cutoff and sensitive, and specific measurement of the expression changes by RT-qPCR is warranted. HsamiR-20a is downregulated by a factor of two or greater in patient samples, infected PBMCs, and anti-CD3 activated $\mathrm{T}$ cells (Figure 4). In the study by Houzet et al. [55], hsa-miR-17-5p reached significant downregulation solely in anti-CD3 activated $\mathrm{T}$ cells (Figure 4 ). In CEMx174/HIV-1 and CEMx174/ $\Delta$ VV, hsa-miR-20a was downregulated by a factor of 1.8 and 2 , respectively; and hsa-miR-17-5p was downregulated by a factor of 2 and 1.9, respectively. Further experiments are warranted to measure the possible upregulation of PCAF and other target genes. The observed downregulation of hsa-miR-17-5p and hsa-miR-20a was greater in CEMx174/RSS compared to HIV-1 (factor of 4). Quantitative measurement by qPCR is necessary to investigate the possibility that Tat RSS fosters a positive feedback loop for expression of PCAF. On the other hand, the level of hsa-miR-198, which targets cyclin T1 [62], is upregulated by all three HIV-1 ${ }^{\text {NL4-3 }}$ strains tested in this study. Cyclin T1 also acts as a cofactor for Tat transcriptional trans-activation, and upregulation of hsa-miR-198 could reduce cyclin T1 levels. The impact on HIV-1 transcription activity remains to be determined and consider in relation to the contributions of cell lineage and activation status.

\section{Conclusions}

HIV $-1^{\text {NL4-3 }}$ perturbs the miRNA expression profile of CEMx174 lymphocytes. The removal of Tat RSS activity from HIV-1 did not globally affect miRNA level, but relaxed the downregulation of a subset of miRNA. Broad similarities in miRNA expression trends were observed in HIV-1 ${ }^{\text {NL4-3 }}$ infected CEMx174 cells and clinical samples from HIV-1 infected patients [55]. The overlapping trends validate that cultured lymphocytes provide a tractable model to develop specific hypotheses of interplay between HIV-1 and miRNA-mediated RNA silencing that inform translational investigations in clinical specimens. The determination that Tat RSS activity affects the expression level of a subset of miRNAs is a necessary step in the process to understand the interface of HIV-1 with host RNA silencing activity. The miRNAs we have determined to be dysregulated by Tat RSS in HIV-1 infected lymphocytes provide a focal point to the MRE and target genes that shape the cellular environment in HIV-1 infection.

Table 7 Cellular miRNAs with published effect on HIV-1 exhibited similar expression trends between indicated infections of CEMx174 lymphocytes

\begin{tabular}{|c|c|c|c|c|}
\hline \multicolumn{4}{|c|}{$\begin{array}{c}\text { Expression Level for } \\
\text { Indicated Infection State Relative to Mock a }\end{array}$} & \multirow[b]{2}{*}{$\begin{array}{l}\text { Targeted Transcript } \\
\text { and Expected Outcome }\end{array}$} \\
\hline miRNA & HIV-1 & RSS & $\Delta \mathrm{VV}$ & \\
\hline hsa-miR-17-5p & 0.5 & 0.3 & 0.4 & $\begin{array}{c}\text { 3'-UTR PCAF } \\
\text { (Triboulet } 2007[15])\end{array}$ \\
\hline hsa-miR-20a & 0.6 & 0.2 & 0.5 & $\begin{array}{l}\text { Upregulation of cofactor } \\
\text { for Tat transcriptional } \\
\text { trans-activation, PCAF }\end{array}$ \\
\hline hsa-miR-150 & 2.1 & 2.7 & 1. 8 & \\
\hline hsa-miR-382 & 1.7 & 1.1 & 1.4 & HIV-1 3'-UTR \\
\hline hsa-miR-125b & 0.2 & 0.3 & 0.2 & $\begin{array}{l}\text { (Huang } 2007[16]) \\
\text { Promotion of viral latency }\end{array}$ \\
\hline hsa-miR-28 & $<\mathrm{MD}$ & $<M D$ & $<\mathrm{MD}$ & in resting $T$ cells \\
\hline hsa-miR-223 & $<\mathrm{MD}$ & $<\mathrm{MD}$ & $<\mathrm{MD}$ & \\
\hline hsa-miR-198 b & 2.1 & 1.7 & 2.1 & $\begin{array}{c}\text { 3'-UTR CCNT1 } \\
\text { (Rice and Sung } 2009 \text { [62]) } \\
\text { Downregulation of } \\
\text { cofactor for Tat } \\
\text { transcriptional trans- } \\
\text { activation, cyclin T1 }\end{array}$ \\
\hline
\end{tabular}

\footnotetext{
${ }^{a}$ Expression trends of indicated cellular miRNAs given for each viral strain relative to uninfected controls.

b $<$ MD: less than the minimum detectable signal.

c Upregulation trend was validated by qRT-PCR on independent infections.
} 


\section{Methods}

\section{Proviruses and cells}

HIV-1 proviral clone NL4-3 was obtained from AIDS Reagent Reference Program. Vpr-deficient HIV-1 provirus pNL4-3-VprX [52] and pNL101- $\Delta$ Vif were obtained from V. Planelles [42]. HIV-1 strain $\Delta \mathrm{VV}$ was constructed by replacing $V$ if open reading frame in pNL4-3-VprX with $\Delta$ Vif from pNL101- $\Delta$ Vif by Nhe IPflM I restriction digest. CEMx174 human lymphocytes were grown in RPMI with $10 \%$ fetal bovine serum and 1\% antibiotic-antimycotic (Gibco). HEK 293 cells were grown in DMEM with $10 \%$ fetal bovine serum and $1 \%$ antibiotic-antimycotic (Gibco).

\section{Transfection, infection and flow cytometry}

Plasmid transfections were conducted with Fugene 6 (Roche) based on manufacturer instruction. HIV-1 virions were propagated by transfection of HEK 293 cells with $10 \mu \mathrm{g}$ of HIV-1 $1^{\mathrm{NL} 4-3}$ or the derivative proviruses. Medium was replaced at 12 hours post-transfection, and virion-containing supernatant medium was collected at three 12 hour intervals for Gag p24 ELISA (Zeptometrix). CEMx174 cells $\left(1 \times 10^{6}\right)$ were incubated with cellfree supernatant medium containing $3 \times 10^{8} \mathrm{pg} / \mathrm{ml}$ of Gag for 48 hours. Subsequently CEMx174 lymphocytes were infected by co-culture, which is more efficient than infection with cell-free virus. Producer cells were isolated on Ficoll and co-cultured with naive CEMx174 at a ratio of 1:10. Progression of the infections was evaluated at regular intervals by FACS of intracellular Gag. Cells were fixed and permeabilized with Cytofix/Cytoperm kit (BD Biosciences) and stained with FITC-conjugated anti-p24 antibody (KC57-FITC, Beckman Coulter). FACS on a BD FACSCalibur was analyzed in CellQuest Pro (BD Biosciences).

\section{Microarray probes, hybridization and analysis}

Total RNA was isolated with Trizol reagent (Invitrogen) and similar RNA quality and concentration were determined by Bioanalyzer (Agilent) and biotin-labeled complementary DNA was generated by reverse transcription. Hybridization was performed at Ohio State University Comprehensive Cancer Center microarray core facility on miRNA microarray chip OSU_CCC version 4.0 that contains 906 human miRNA probes potted in duplicate, with two or three independent biological replicates. The chip captures 518 mature miRNA and 332 precursors [53]. GenePix Pro 6 image analysis software was used to quantify the signals detected by the array scanner. Background subtracted signal intensity was obtained for each spot on the chip and averaged over duplicate probe sets before log base 2 transformation. Quantile normalization was utilized to normalize experimental variation among chips [67]. Normalized expression values of each miRNA probe set were averaged over at least two samples of each virus infection and expression ratios were calculated between virus infections. Blank spots on the chip were used to evaluate the signal measurement uncertainty. Microarray data deposited at NCBI Gene Expression Omnibus [68] are accessible through GEO Series accession number [GSE:21892] (http://www.ncbi. nlm.nih.gov/geo/query/acc.cgi?acc=GSE21892). Statistical software $\mathrm{R}$ was employed for data manipulation. Aggregate data was analyzed in Microsoft Excel by the use of pivot tables. Probe expression levels were scored as above or below minimal detectable levels (cutoff $\log _{2}$ $=5$ ), and only those probes above minimal detectable limits were used in analysis. Ratios of expression compared to mock infection were calculated for each viral infection and each miRNA probe and used to construct scatterplots.

\section{Reverse transcription and real-time PCR}

We prepared cDNA from 10 ng total cellular RNA using the Taqman MicroRNA Reverse Transcription kit (Applied Biosciences) and the appropriate primer from the Taqman MicroRNA Assay (Applied Biosciences). According to the manufacturer's protocol, $1.33 \mu \mathrm{L}$ was carried forward into the PCR reaction with Taqman Universal Master Mix II (Applied Biosciences). LightCycler 480 (Roche) was used to collect and analyze data. Dilution curves were generated for each probe assayed and used to determine probe efficiency. Efficiency-corrected abundances of $\mathrm{miR}-29 \mathrm{a}, \mathrm{miR}-128, \mathrm{miR}-198$, and miR-214 were determined relative to internal control snoRNA RNU48, and expression relative to mock infection was calculated using the $\Delta \Delta \mathrm{C}_{\mathrm{T}}$ method [61].

\footnotetext{
Acknowledgements

We thank Mr. Tim Vojt for illustration; Dr. Vicente Planelles for pNL4-3-VprX and pNL101- $\triangle$ Vif; Dr. Alper Yilmaz for construction of HIV ${ }^{N L 4-3} \Delta W_{\text {; }}$ and OSU Comprehensive Cancer Center Microarray Shared Resource for microarray data collection. This work was funded by NIH RO1CA108882 and P30CA100730 to KBL; and P01CA16058 to the OSU Comprehensive Cancer Center.
}

\section{Author details}

${ }^{1}$ Department of Veterinary Biosciences; Center for Retrovirus Research; Center for RNA Biology; Comprehensive Cancer Center, Ohio State University, Columbus OH, USA. ${ }^{2}$ Molecular, Cellular \& Developmental Biology Graduate Program, Ohio State University, Columbus OH, USA. ${ }^{3}$ Center for Biostatistics, Ohio State University Comprehensive Cancer Center, Columbus OH, USA.

\section{Authors' contributions}

SQ and KBL designed the experiments; SQ performed sample preparation for analysis by the Microarray Core of the OSU Comprehensive Cancer Center; LY performed the biostatistics analysis of microarray data; $\mathrm{AMH}$ analyzed microarray data and performed experiments. $\mathrm{KBL}$ and $\mathrm{AMH}$ prepared the manuscript. All authors read and approved the final manuscript. 


\section{Competing interests}

The authors declare that they have no competing interests.

Received: 20 November 2009 Accepted: 13 May 2011

Published: 13 May 2011

\section{References}

1. Friedman RC, Farh $\mathrm{KKH}$, Burge $\mathrm{CB}$, Bartel DP: Most mammalian mRNAs are conserved targets of microRNAs. Genome Res 2009, 19:92-105.

2. Flynt AS, Lai EC: Biological principles of microRNA-mediated regulation: shared themes amid diversity. Nat Rev Gen 2008, 9:831-842.

3. Garzon R, Calin GA, Croce CM: MicroRNAs in cancer. Annu Rev Med 2009, 60:167-179.

4. Winter J, Jung S, Keller S, Gregory RI, Diederichs S: Many roads to maturity: microRNA biogenesis pathways and their regulation. Nat Cell Biol 2009, 11:228-234.

5. Li WX, Ding SW: Viral suppressors of RNA silencing. Curr Opin Biotechnol 2001, 12:150-154.

6. Diaz-Pendon JA, Ding SW: Direct and indirect roles of viral suppressors of RNA silencing in pathogenesis. Annu Rev Phytopathol 2008, 46:303-326.

7. Li F, Ding SW: Virus counterdefense: Diverse strategies for evading the RNA-silencing immunity. Annu Rev Microbiol 2006, 60:503-531.

8. de Vries W, Berkhout B: RNAi suppressors encoded by pathogenic human viruses. Int J Biochem Cell Biol 2008, 40:2007-2012.

9. Haasnoot J, de Vries W, Geutjes EJ, Prins M, de Haan P, Berkhout B: The Ebola virus VP35 protein is a suppressor of RNA silencing. PLOS Pathog 2007, 3:794-803.

10. Fabozzi G, Nabel CS, Dolan MA, Sullivan MJ: Ebolavirus proteins suppress siRNA effects by direct interaction with the mammalian RNAi pathway. $J$ Virol 2011.

11. de Vries W, Haasnoot J, Fouchier R, de Haan P, Berkhout B: Differential RNA silencing suppression activity of NS1 proteins from different influenza A virus strains. J Gen Virol 2009, 90:1916-1922.

12. Abe M, Suzuki H, Nishitsuji H, Shida H, Takaku H: Interaction of human Tcell lymphotropic virus type I Rex protein with Dicer suppresses RNAi silencing. FEBS Lett 2010, 584:4313-4318.

13. Lu SH, Cullen BR: Adenovirus VA1 noncoding RNA can inhibit small interfering RNA and microRNA biogenesis. J Virol 2004, 78:12868-12876.

14. Qian S, Zhong X, Yu L, Ding B, de Haan P, Boris-Lawrie K: HIV-1 Tat RNA silencing suppressor activity is conserved across kingdoms and counteracts translational repression of HIV-1. Proc Natl Acad Sci USA 2009, 106:605-610.

15. Triboulet R, Mari B, Lin YL, Chable-Bessia C, Bennasser Y, Lebrigand $K$, Cardinaud B, Maurin T, Barbry P, Baillat V, Reynes J, Corbeau P, Jeang KT, Benkirane M: Suppression of microRNA-silencing pathway by HIV-1 during virus replication. Science 2007, 315:1579-1582.

16. Huang JL, Wang FX, Argyris E, Chen KY, Liang ZH, Tian H, Huang WL, Squires $\mathrm{K}$, Verlinghieri $\mathrm{G}$, Zhang H: Cellular microRNAs contribute to HIV-1 latency in resting primary CD4(+) T lymphocytes. Nat Med 2007, 13:1241-1247.

17. Chable-Bessia C, Meziane O, Latreille D, Triboulet R, Zamborlini A, Wagschal A, Jacquet JM, Reynes J, Levy Y, Saib A, Bennasser Y, Benkirane M: Suppression of HIV-1 replication by microRNA effectors. Retrovirology 2009, 6:26.

18. Klase Z, Kale P, Winograd R, Gupta MV, Heydarian M, Berro R, McCaffrey T, Kashanchi F: HIV-1 TAR element is processed by Dicer to yield a viral micro-RNA involved in chromatin remodeling of the viral LTR. BMC Mol Biol 2007, 8:63.

19. Ouellet D, Plante I, Landry P, Barat C, Janelle M, Flamand L, Tremblay M, Provost P: Identification of functional microRNAs released through asymmetrical processing of HIV-1 TAR element. Nucleic Acids Res 2008, 36:2353-2365.

20. Klase Z, Winograd R, Davis J, Carpio L, Hildreth R, Heydarian M, Fu S, McCaffrey T, Meiri E, Ayash-Rashkovsky M, Gilad S, Bentwich Z, Kashanchi F: HIV-1 TAR miRNA protects against apoptosis by altering cellular gene expression. Retrovirology 2009, 6:18

21. Bennasser $Y$, Le SY, Benkirane M, Jeang KT: Evidence that HIV-1 encodes an siRNA and a suppressor of RNA silencing. Immunity 2005, 22:607-619.

22. Lin J, Cullen BR: Analysis of the interaction of primate retroviruses with the human RNA interference machinery. J Virol 2007, 81:12218-12226.
23. Ouellet D, Plante I, Barat C, Tremblay M, Provost P: Emergence of a complex relationship between HIV-1 and the microRNA pathway. Methods Mol Biol 2009, 487:415-433.

24. Haasnoot J, Westerhout EM, Berkhout B: RNA interference against viruses: strike and counterstrike. Nat Biotechnol 2007, 25:1435-1443.

25. Schnettler E, de Vries W, Hemmes H, Haasnoot J, Kormelink R, Goldbach R, Berkhout B: The NS3 protein of rice hoja blanca virus complements the RNAi suppressor function of HIV-1 Tat. EMBO Rep 2009, 10:258-263.

26. Bennasser $Y$, Yeung $M L$, Jeang $K T$ : HIV-1 TAR RNA subverts RNA interference in transfected cells through sequestration of TAR RNAbinding protein, TRBP. J Biol Chem 2006, 281:27674-27678.

27. Ong CL, Thorpe JC, Gorry PR, Bannwarth S, Jaworowski A, Howard IL, Chung S, Campbell S, Christensen HS, Clerzius G, Mouland AJ, Gatignol A, Purcell DFJ: Low TRBP levels support an innate human immunodeficiency virus type 1 resistance in astrocytes by enhancing the PKR antiviral response. J Virol 2005, 79:12763-12772.

28. Haase AD, Jaskiewicz L, Zhang HD, Laine S, Sack R, Gatignol A, Filipowicz W: TRBP, a regulator of cellular PKR and HIV-1 virus expression, interacts with Dicer and functions in RNA silencing. EMBO Rep 2005, 6:961-967.

29. Chendrimada TP, Gregory RI, Kumaraswamy E, Norman J, Cooch N, Nishikura K, Shiekhattar R: TRBP recruits the Dicer complex to Ago2 for microRNA processing and gene silencing. Nature 2005, 436:740-744.

30. Gatignol A, Laine S, Clerzius G: Dual role of TRBP in HIV replication and RNA interference: viral diversion of a cellular pathway or evasion from antiviral immunity? Retrovirology 2005, 2:65.

31. Gatignol A, Bucklerwhite A, Berkhout B, Jeang KT: Characterization of a human TAR RNA-binding protein that activates the HIV-1 LTR. Science 1991, 251:1597-1600.

32. Gatignol A, Kumar A, Rabson A, Jeang KT: Identification of cellular proteins that bind to the human immunodeficiency virus type- 1 transactivation-responsive TAR element RNA. Proc Natl Acad Sci USA 1989, 86:7828-7832.

33. Park HS, Davies MV, Langland JO, Chang HW, Nam YS, Tartaglia J, Paoletti E, Jacobs BL, Kaufman RJ, Venkatesan S: TAR RNA-binding protein is an inhibitor of the interferon-induced protein-kinase PKR. Proc Natl Acad Sci USA 1994, 91:4713-4717.

34. Selby MJ, Bain ES, Luciw PA, Peterlin BM: Structure, sequence, and position of the stem loop in TAR determine transcriptional elongation by Tat through the HIV-1 long terminal repeat. Genes \& Development 1989, 3:547-558.

35. Carleton M, Cleary MA, Linsley PS: MicroRNAs and cell cycle regulation. Cell Cycle 2007, 6:2127-2132.

36. Cloonan N, Brown MK, Steptoe AL, Wani S, Chan WL, Forrest AR, Kolle G, Gabrielli B, Grimmond SM: The miR-17-5p microRNA is a key regulator of the G1/S phase cell cycle transition. Genome Biology 2008, 9:R127.

37. Reinhart BJ, Slack FJ, Basson M, Pasquinelli AE, Bettinger JC, Rougvie AE, Horvitz HR, Ruvkun G: The 21-nucleotide let-7 RNA regulates developmental timing in Caenorhabditis elegans. Nature 2000, 403:901-906.

38. Legesse-Miller A, Elemento O, Pfau S, Forman J, Tavazoie S, Coller H: let-7 overexpression leads to an increased fraction of cells in $G 2 / M$, direct down-regulation of $\mathrm{Cdc} 34$ and stabilization of Wee1 kinase in primary fibroblasts. J Biol Chem 2009, 284:6605-6609.

39. Liu M, Wu HD, Liu T, Li YX, Wang F, Wan HY, Li X, Tang H: Regulation of the cell cycle gene, BTG2, by miR-21 in human laryngeal carcinoma. Cell Res 2009, 19:828-837.

40. Bandi N, Zbinden SZ, Gugger M, Arnold M, Kocher V, Hasan L, Kappeler A, Brunner T, Vassella E: MiR-15a and miR-16 are implicated in cell cycle regulation in a $\mathrm{Rb}$-dependent manner and are frequently deleted or down-regulated in non-small cell lung cancer. Cancer Res 2009, 69:5553-5559.

41. Jowett JBM, Planelles V, Poon B, Shah NP, Chen ML, Chen ISY: The humanimmunodeficiency-virus type-1 vpr gene arrests infected T-cells in the $G$ (2)+M phase of the cell-cycle. J Virol 1995, 69:6304-6313.

42. Dehart JL, Bosque A, Harris RS, Planelles V: Human immunodeficiency virus type 1 vif induces cell cycle delay via recruitment of the same E3 ubiquitin ligase complex that targets APOBEC3 proteins for degradation. J Virol 2008, 82:9265-9272.

43. Sakai K, Dimas J, Lenardo MJ: The Vif and Vpr accessory proteins independently cause HIV-1-induced T cell cytopathicity and cell cycle arrest. Proc Natl Acad Sci USA 2006, 103:3369-3374. 
44. Rogel ME, Wu LI, Emerman M: The human-immunodeficiency-virus type-1 vpr gene prevents cell-proliferation during chronic infection. J Virol 1995, 69:882-888.

45. Andersen J, Le Rouzic E, Planelles V: HIV-1 Vpr: mechanisms of G2 arrest and apoptosis. Exp Mol Pathol 2008, 85:2-10.

46. Sheehy AM, Gaddis NC, Choi JD, Malim MH: Isolation of a human gene that inhibits HIV-1 infection and is suppressed by the viral Vif protein. Nature 2002, 418:646-650.

47. Kao S, Khan MA, Miyagi E, Plishka R, Buckler-White A, Strebel M: The human immunodeficiency virus type 1 Vif protein reduces intracellular expression and inhibits packaging of APOBEC3G (CEM15), a cellular inhibitor of virus infectivity. J Virol 2003, 77:11398-11407.

48. Wang JF, Shackelford JM, Selliah N, Shivers DK, O'Neill E, Garcia JV, Muthumani K, Weiner D, Yu XF, Gabuzda D, Finkel TH: The HIV-1 Vif protein mediates degradation of $\mathrm{Vpr}$ and reduces $\mathrm{Vpr}$-induced cell cycle arrest. DNA Cell Biol 2008, 27:267-U38.

49. Pietroboni G, Harnett G, Bucens M: Centrifugal enhancement of human immunodeficiency virus (HIV) and human herpesvirus type 6 (HHV-6) infection in vitro. J Virol Meth 1989, 24:85-90.

50. Ho WZ, Cherukuri R, Ge SD, Cutilli JR, Song L, Whitko S, Douglas SD: Centrifugal enhancement of human-immunodeficiency-virus type-1 infection and human cytomegalovirus gene-expression in human primary monocyte macrophages in vitro. J Leukoc Biol 1993, 53:208-212.

51. Sato H, Orenstein J, Dimitrov D, Martin M: Cell-to-cell spread of HIV-1 occurs within minutes and may not involve the participation of virus particles. Virology 1992, 186:712-724.

52. Planelles V, Jowett JBM, Li QX, Xie YM, Hahn B, Chen ISY: Vpr-induced cell cycle arrest is conserved among primate lentiviruses. J Virol 1996, 70:2516-2524.

53. Liu CG, Calin GA, Meloon B, Gamliel N, Sevignani C, Ferracin M, Dumitru CD, Shimizu M, Zupo S, Dono M, Alder H, Bullrich F, Negrini M, Croce CM: An oligonucleotide microchip for genome-wide microRNA profiling in human and mouse tissues. Proc Natl Acad Sci USA 2004, 101:9740-9744.

54. Yeung ML, Bennasser $Y$, Myers TG, Jiang GJ, Benkirane $M$, Jeang $K T$ : Changes in microRNA expression profiles in HIV-1-transfected human cells. Retrovirology 2005, 2:81.

55. Houzet L, Yeung ML, de Lame $V$, Desai D, Smith SM, Jeang KT: MicroRNA profile changes in human immunodeficiency virus type 1 (HIV-1) seropositive individuals. Retrovirology 2008, 5:118.

56. Krichevsky AM, King KS, Donahue CP, Khrapko K, Kosik KS: A microRNA array reveals extensive regulation of microRNAs during brain development. RNA 2003, 9:1274-1281.

57. Santhakumar D, Forster T, Laqtom NN, Fragkoudis R, Dickinson P, AbreuGoodger C, Manakov SA, Choudhury NR, Griffiths SJ, Vermeulen A, Enright AJ, Dutia B, Kohl A, Ghazal P, Buck AH: Combined agonistantagonist genome-wide functional screening identifies broadly active antiviral microRNAs. Proc Natl Acad Sci USA 2010, 107:13830-13835.

58. Pedersen IM, Cheng G, Wieland S, Volinia S, Croce CM, Chisari FV, David M: Interferon modulation of cellular microRNAs as an antiviral mechanism. Nature 2007, 449:919-U13.

59. Chang KH, Mestdagh P, Vandesompele J, Kerin MJ, Miller N: MicroRNA expression profiling to identify and validate reference genes for relative quantification in colorectal cancer. Bmc Cancer 2010, 10:173.

60. Davoren PA, McNeill RE, Lowery AJ, Kerin MJ, Miller N: Identification of suitable endogenous control genes for microRNA gene expression analysis in human breast cancer. BMC Mol Biol 2008, 9:76.

61. Livak KJ, Schmittgen TD: Analysis of relative gene expression data using real-time quantitative PCR and the 2(T)(-Delta Delta C) method. Methods 2001, 25:402-408.

62. Sung TL, Rice AP: MiR-198 inhibits HIV-1 gene expression and replication in monocytes and its mechanism of action appears to involve repression of cyclin T1. PLOS Pathog 2009, 5:e1000263.

63. Re MC, Vitone F, Biagetti C, Schiavone P, Alessandrini F, Bon I, de Crignis E, Gibellini D: HIV-1 DNA proviral load in treated and untreated HIV-1 seropositive patients. Clin Microbiol Infect 2010, 16:640-646.

64. Vargason JM, Szittya G, Burgyan J, Hall TMT: Size selective recognition of siRNA by an RNA silencing suppressor. Cell 2003, 115:799-811.

65. Baccarini A, Chauhan H, Gardner TJ, Jayaprakash AD, Sachidanandam R, Brown BD: Kinetic analysis reveals the fate of a microRNA following target regulation in mammalian cells. Curr Biol 2011, 21:369-376.
66. Dorr A, Kiermer V, Pedal A, Rackwitz HR, Henklein P, Schubert U, Zhou MM, Verdin E, Ott M: Transcriptional synergy between Tat and PCAF is dependent on the binding of acetylated Tat to the PCAF bromodomain. EMBO J 2002, 21:2715-2723.

67. Rao YL, Lee Y, Jarjoura D, Ruppert AS, Liu CG, Hsu JC, Hagan JP: A comparison of normalization techniques for microRNA microarray data. Stat Appl Genet Mol Biol 2008, 7:22

68. Edgar R, Domrachev M, Lash AE: Gene Expression Omnibus: NCBI gene expression and hybridization array data repository. Nucleic Acids Res 2002, 30:207-210.

69. Griffith-Jones S: The miRNA registry. Nucleic Acids Res 2004, 32:D109-D111.

doi:10.1186/1742-4690-8-36

Cite this article as: Hayes et al:: Tat RNA silencing suppressor activity contributes to perturbation of lymphocyte miRNA by HIV-1. Retrovirology $20118: 36$.

\section{Submit your next manuscript to BioMed Central and take full advantage of:}

- Convenient online submission

- Thorough peer review

- No space constraints or color figure charges

- Immediate publication on acceptance

- Inclusion in PubMed, CAS, Scopus and Google Scholar

- Research which is freely available for redistribution

Submit your manuscript at www.biomedcentral.com/submit
C) Biomed Central 